\title{
JURISPRUDENCIA AMBIENTAL EN ARAGÓN (PRIMER SEMESTRE 2017)
}

\author{
Laura Salamero TeIXIDÓ
}

Profesora ayudante doctora

Universidad de Lleida 
Sumario: 1. El Tribunal Superior de Justicia de Aragón confirma de nuevo la legalidad del impuesto sobre el daño medioambiental causado por la instalación de transportes por cable. 2. Sobre la arbitrariedad en el procedimiento de autorización de vertidos al dominio público hidráulico. 3. policía de aguas: sobre la legalidad de la sanción por infracciones en materia de aguas. 4. Sobre el valor de los informes en el procedimiento de concesión de captación de aguas.

\section{El Tribunal Superior de Justicia de Aragón confirma de nuevo la} legalidad del impuesto sobre el daño medioambiental causado por la instalación de transportes por cable

En la Sentencia núm. 209/2017, de 10 de mayo, la Sala de lo ContenciosoAdministrativo del Tribunal Superior de Justicia de Aragón vuelve a resolver sobre la adecuación al ordenamiento jurídico del impuesto sobre las instalaciones de transporte por cable.

Es preciso recordar que el impuesto medioambiental sobre las instalaciones de transporte por cable fue creado por la Ley 13/2005, de 30 de diciembre, de Medidas Fiscales y Administrativa en materia de Tributos Cedidos y Tributos Propios de la Comunidad Autónoma de Aragón; y se desarrollaba en la Orden de 12 de mayo de 2006. No obstante, el impuesto fue derogado por la Ley 3/2012, de 8 de marzo, de Medidas Fiscales y Administrativas de la Comunidad Autónoma de Aragón, si bien la Ley 10/2015, de 28 de diciembre, de medidas para el mantenimiento de los servicios públicos en la Comunidad Autónoma de Aragón, lo recuperó. Actualmente se encarga de su desarrollo el Decreto $1 / 2007$, de 16 de enero.

En sentencia de 8 de junio la Sala de lo Contencioso-Administrativo, Sección 2. a , del Tribunal Supremo (recurso de casación 855/2014), se estimó que dicho impuesto se ajustaba a la legalidad. Dicho pronunciamiento fue objeto de comentario en esta misma Revista (núm. 2, 2016).

Pues bien, el recurso que resuelve el Tribunal Superior de Justicia Aragonés ha sido interpuesto por la misma recurrente que interpuesto el recurso de casación anteriormente mencionado. De nuevo, la parte aduce que se vulnera el «principio de capacidad económica, la falta de daño medioambiental derivado de la instalación de la recurrente y que la cobertura económica del daño, de haberlo, se halla ya lograda mediante la exacción relativa a la ocupación del 
monte público». Para resolver el pleito, el Tribunal recurre a su propia jurisprudencia dictada en la materia, así como en la ya mentada sentencia del TS dictada en casación, desestimando en consecuencia el recurso.

De forma sintética, los argumentos del TSJ aragonés estriban en reafirmar la finalidad de tutela medioambiental del tributo, y por lo tanto no hay un solapamiento con el impuesto sobre actividades económicas.

\section{Sobre la arbitrariedad en el procedimiento de autorización de vertidos al dominio público hidráulico.}

La Sentencia analizada trae causa de la denegación de una autorización de vertidos al dominio público asociadas a la ejecución de obras para el acceso a una estación de servicio mediante un puente de acceso sobre el arroyo Urrizabaleta. La estación de servicio está ubicada en el Parque Comercial Goberia, en Etxabarri-lbiña, Zigoitia (Ávila).

Es preciso en primer lugar destacar que la competencia del TSJ aragonés deriva del hecho que la parte recurrida es la Confederación Hidrográfica del Ebro, pues es el órgano de cuenca encargado de la autorización en cuestión, y su sede se halla en Zaragoza (art. 2 del Real Decreto 931/1989, de 21 de julio, por el que se constituye el Organismo de cuenca Confederación Hidrográfica del Ebro); así en virtud del art. 14.1. primera de la Ley 29/1998, de 13 de julio, reguladora de la Jurisdicción Contencioso-administrativa, «con carácter general, será competente el órgano jurisdiccional en cuya circunscripción tenga su sede el órgano que hubiere dictado la disposición o el acto originario impugnado».

La resolución denegatoria de la autorización que se impugna se basa en la propuesta de resolución desfavorable de la Agencia Vasca del Agua, así como en varios informes emitidos por la misma Agencia, en los que se argumenta, entre otros que «el emplazamiento de una gasolinera en la parcela catastral 210 Etxabarri-lbiña (Zigoitia) no es adecuado, en la medida de que se considera no compatible con las captaciones de aguas preexistentes 
(manantial Venta Caída y sondeo PET) y con la adecuada protección de los recursos hídricos subterráneos del entorno». Asimismo, se afirma que «[l]a actividad de la estación de servicio que se pretende instalar, puede provocar la contaminación o degradación del dominio público hidráulico, por lo que debería informarse desfavorablemente sobre su implantación de acuerdo con lo establecido en el art. 97 del R.D.L. 1/2001, de 20 de julio, por el que se aprueba el texto refundido de la Ley de Aguas». La actora, con fundamento a varios informes periciales aportados de parte, argumenta que la denegación de la administración es arbitraria, basada en una interpretación errónea del principio de cautela y de acción preventiva.

EI TSJ aragonés, que desestima el recurso, argumenta sobradamente que la decisión denegatoria de la Administración en ningún caso es arbitraria a la luz de los informes de la Agencia Vasca del Agua en los que se basa. Informes a los que entiende que debe darse prevalencia por encima de los de parte puesto que «[l]os estudios específicos realizados en los informes mencionados se refieren de forma singular a la parcela en cuestión y la zona hidrogeológica en la que se sitúa y por esta razón debe darse prevalencia a los mismos frente a otros elementos comparativos que se introducen en la demanda». Ello descarta que la denegación de la autorización haya sido arbitraria.

\section{Policía de aguas: sobre la legalidad de la sanción por infracciones en materia de aguas.}

En la Sentencia 241/2017, de 29 de mayo, el Tribunal Superior de Justicia de Aragón confirma la legalidad de dos sanciones, que acumuladas suman $1.500 €$, impuestas por la comisión de dos infracciones leves: de un lado, derivar agua de un barranco de Serull sin disponer de la preceptiva concesión y, del otro, la ocupación el dominio público hidráulico mediante la infraestructura de captación del mismo barranco mediante una rejilla de entrada de agua, sin autorización previa de la administración hidráulica. Las sanciones se imponen con arreglo a los arts. 116.3.b) y 116.3.e) del Real Decreto Legislativo 1/2001, de 20 de julio, por el que se aprueba el texto refundido de la Ley de Aguas y el art. 315.m) y 315.d) del Real Decreto 
849/1986, de 11de, por el que se aprueba el Reglamento del Dominio Público Hidráulico.

Además de algunos argumentos formales espurios, la parte actora, Endesa Generación, alega en cuanto al fondo que disponía de autorización para la capación del agua. En concreto sostiene que «por O. M. de 27 de julio de 1948 Catalana de Gas y Electricidad S. A. obtuvo conexión para el aprovechamiento hidráulico de la zona del Lago de San Mauricio, en la que se sitúa el barranco de Serull. Que por O. M. de 21 de junio de 1954 dicha concesión fue transferida a Hidroeléctrica de Cataluña, S. A., y posteriormente a Hidroeléctrica Ribagorzana, S. A. (Enher), luego Fecsa- Enher. Finalmente pasa a Endesa Generación S. A. en fecha 25 de febrero de 2008. Aprovechamiento que incluía la ocupación en lo necesario del dominio público hidráulico». Ante tal argumento el Tribunal arguye que «no está comprobado que la concesión incluyese el aprovechamiento en el referido barranco, ni tampoco la ocupación de dominio público hidráulico en las coordenadas a que se refiere la resolución impugnada. Las conclusiones de la demandante difieren del contenido de los informes de la CHE, que se expresan en sentido negativo a tal inclusión».

Por último, la demandante esgrime que las sanciones han prescrito transcurridos 6 meses desde su comisión, y fija la fecha de inicio de la prescripción el 18 de mayo de 1954, fecha del acta de autorización de puesta en marcha del aprovechamiento hidráulico del Salto de San Mauricio. Ante tal argumento, el TSJ aragonés pone de manifiesto que la derivación de aguas y por la ocupación de dominio público hidráulico, son infracciones llamadas continuadas o permanentes, «con la consecuencia de que los plazos de prescripción se computarán, respectivamente, desde el día en que se realizó la última infracción, desde que se eliminó la situación ilícita o desde que cesó la conducta».

Por todo ello, se desestima el recurso y declaran ajustadas a derecho las sanciones indicadas. 


\section{Sobre el valor de los informes en el procedimeinto de concesión de captación de aguas.}

La Sentencia 245/2017, de 31 de mayo de 2017, del Tribunal Superior de Justicia enfrenta a la Diputación provincial de Huesca y el Ayuntamiento de Yésero, de un lado y, del otro, la Administración General del Estado.

El litigio en cuestión trae causa de los siguientes hechos. El Ayuntamiento de Yésero solicitó el 22 de septiembre de 1999 una autorización de aprovechamiento de aguas subterráneas a derivar de manantial en el término municipal de Yésero (Huesca), que se tramitó conforme a lo dispuesto en el Reglamento del Dominio Público Hidráulico. El expediente siguió su tramitación hasta que el 24 de mayo de 2007 el Presidente de la CHE acordó ofrecer al Ayuntamiento de Yésero la concesión de un aprovechamiento de aguas públicas de dos manantiales, con un caudal medio equivalente en el mes de máximo consumo de $0,98 \mathrm{l} / \mathrm{s}$ para el conjunto de todas las tomas y volumen máximo anual de 12.562 m3/año, destinado a abastecimiento de población en el mismo término mencionado. El Ayuntamiento de Yésero no contestó a dicho ofrecimiento de condiciones. El 26 de marzo de 2010 se volvió a reiterar el ofrecimiento de condiciones para el otorgamiento de la concesión y, de nuevo, el Ayuntamiento no respondió al mismo, motivo por el que conforme al art. 116 del Reglamento del Dominio Público Hidráulico el 15 de diciembre de 2010 se acordó archivar la solicitud de concesión del aprovechamiento de aguas por no haber aceptado el solicitante las condiciones que habían de regir la mencionada concesión. Tal precepto indica en su segundo párrafo que «[s]i el peticionario no contestase al ofrecimiento de condiciones en el plazo indicado, se reiterará aquél de nuevo, para que lo haga en el plazo de diez días, con la advertencia de que, en caso de no contestar, se entenderá que desiste de la petición, de concesión, archivándose el expediente o prosiguiendo el mismo con los restantes peticionarios, si los hubiera».

Notificado este archivo al Ayuntamiento, este formuló recurso de reposición que fue estimado por resolución de 16 de marzo de 2012. Se decidió entonces que por economía procesal se reabría la tramitación del expediente concesional y se tenía en cuenta la aceptación que ahora sí acompañaba el ayuntamiento. 
En fecha 24 de junio de 2014, la CEH otorgó la concesión de un aprovechamiento de aguas públicas a derivar de las Fuentes de El Ángel y Erata a favor del Ayuntamiento de Yésero. Ahora bien, cuando la CHE otorgó dicha concesión desconocía dos informes desfavorables del INAGA emitidos en 2009 y 2011, que informaban en contra del aprovechamiento con motivo de la detección de una determinada rana el paraje que podía verse perjudicada. Dichos informes no fueron traslados al dictarlos a la CHE. De ahí el desconocimiento.

Al tener la CHE conocimiento de dicho informes, resolvió favorablemente dos recursos de reposición acumulados interpuestos por la Asociación Cultural del Sía y Ecologistas en Acción -ADEPA-, denegando la captación de agua y ordenando el cese de las obras.

Entre los argumentos de la Diputación provincial de Huesca y el Ayuntamiento de Yésera destaca el siguiente. Alegan las recurrentes la nulidad de los informes del INAGA, porque ellos ponen de manifiesto un cambio de criterio sin que se realizaran ningún procedimiento revisorio, de modo que los informes que varían o cambian los criterios respecto a informes anteriores sin dicho procedimiento, son nulos de pleno derecho. Ante tal argumento, el TSJ Aragonés arguye que dichos informes son actos de trámite y que, como tales, no pueden ser objeto de impugnación autónoma e independiente ni en vía administrativa ni en vía judicial y, por lo tanto, tampoco pueden ser objeto de un proceso de revisión de oficio. Alegan también los recurrentes que los informes en los que se basa la denegación no son suficientemente fundamentados, pero las partes no son capaces de probar que la rana de marras no se halla en dichas fuentes. Por todo ello, el TSJ de Aragón desestima el recurso. 